\section{A ANTROPOFAGIA NOS UNE?}

Uma das chaves para pensar as ciências humanas produzidas no Brasil está na antropofagia. Com origem na literatura-ou, mais precisamente, na "única filosofia original brasileira”, como provoca Augusto de Campos (1976), em introdução à edição fac-similar do Manifesto antropófago, originalmente publicado em 1928 - a antropofagia, expressa pelas obras de Oswald de Andrade, incluindo seus manifestos dos anos 1920, ainda hoje é referência na reflexão sobre a especificidade da produção brasileira em ciências humanas e sociais - aliás, cuja relevância científica é "de ponta", segundo levantamento do jornal Folha de $S$. Paulo, publicado em 15/6/2019, a despeito de sua crescente desvalorização. "Só a antropofagia nos une. Socialmente. Economicamente. Filosoficamente", diz o primeiro aforismo do Manifesto antropófago. No lugar do ser ou não ser ("to be or not to be?"), do Hamlet de Shakespeare, referencial do patriarcado ocidental, o "tupi or not tupi" representaria a vingança tupinambá de viés matriarcal, expressando uma potência particular do pensamento para a reflexão social, política, linguística e artística do mundo. Hoje, perto do centenário da década em que os manifestos de Oswald de Andrade foram publicados (em 1924, Manifesto da poesia pau-bra-

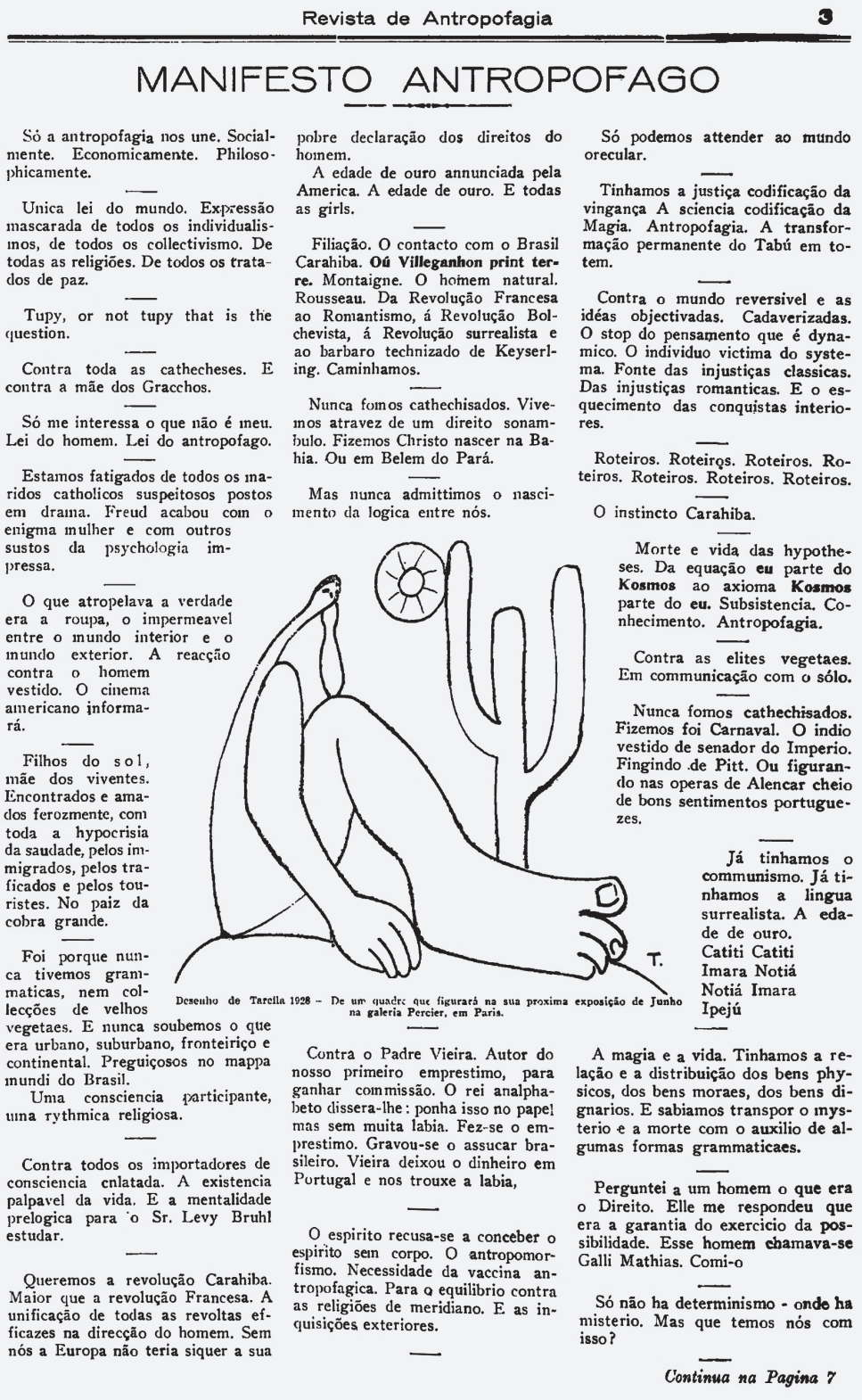

Antropofagia é referência nas ciências humanas e sociais

sil, e, em 1928, Manifesto antropófago), pesquisadores encontram um denominador comum da produção científica nativa e, ao mesmo tempo, reveem a ideia mais difundida sobre o tema: a de que deglutimos o que vem do exterior.
DEVORAR X DIGERIR A artista e pesquisadora Beatriz Azevedo, que publicou Antropofagia palimpsesto selvagem (Cosac Naify, 2016) a partir de sua tese de mestrado em teoria literária na Universidade de São Paulo (USP), questiona o senso co- 
mum que afirma que a postura antropofágica poderia ser resumida na ideia de "digerir a contribuição estrangeira" misturando-a com a cultura nacional. "A antropofagia é muito mais rica que este pressuposto, e, portanto, requer que se leve em consideração tanto o ritual ameríndio que inspirou Oswald de Andrade, como o próprio $M a$ nifesto antropófago. Em ambos os casos, não se trata de 'digerir o estrangeiro', mas de 'devorar o inimigo', atuando de forma crítica em relação ao processo brutal da colonização", define.

Para a pesquisadora, é preciso questionar a percepção simplista de que o procedimento antropófago trata da absorção de conteúdos estrangeiros e da "deglutição" de tais alimentos importados junto aos elementos nacionais. Para ela, a antropofagia, enquanto "revolução caraíba”, objetiva inverter o vetor colonial. "Acredito que o procedimento antropófago trata da valorização da experiência dos povos originários, $\mathrm{da}$ 'contribuição milionária de todos os erros', que deveriam ser 'exportados'”, afirma Azevedo. "Afinal, 'sem nós a Europa não teria sequer a sua pobre Declaração dos Direitos do Homem', e 'antes dos portugueses descobrirem o Brasil, o Brasil havia descoberto a felicidade" " diz ela, referindo-se ao manifesto de 1928. No caso da produção de conhecimento e da literatura, o Brasil estaria se voltando cada vez mais para as criaçóes dos povos ameríndios, "com quem todos nós temos muito a aprender", acrescenta a pesquisadora.
CAMINHO PARA A CIÊNCIA Também para o antropólogo e professor do Centro de Filosofia e Ciências Humanas da Universidade Federal do Acre (UFAC), Marcos de Almeida Matos, a força da antropofagia vem do olhar ameríndio: "Acredito que a potencialidade antropófaga da ciência brasileira está mais em abrir-se ao que sabem os povos tradicionais no Brasil para colocar esse saber em diálogo com o que se produz em outros países, do que em simplesmente deglutir a produção estrangeira acrescentando-lhe um tempero brasileiro", afirma.

O caminho de vanguarda que Oswald de Andrade abre à ciência brasileira é permanente, na opinião de Matos. "Qualquer um que observe com atenção o que se produz de mais significativo na ciência brasileira (em virtualmente qualquer área do conhecimento) verá ali, ao menos em parte dessa produção, a inspiração, a ajuda, o diálogo ou a participação ativa de mestres, xamãs, mateiros, matutos, pescadores, caçadores, rezadeiras, garrafeiros e de outros sujeitos que atuam como guias, interlocutores, ajudantes, copesquisadores etc., de maneira mais ou menos reconhecida pelos doutores das universidades, mas não obstante incontornável”, observa.

Para ele, em nossa história intelectual, pensar o que poderia distinguir o Brasil do resto do Ocidente era tomar nossa particularidade como "maldição", um limite incontornável (o patrimonialismo, a cordialidade, o subdesenvolvimento...), ou então como grande vantagem (o carnaval, a riqueza multicultural, a mistura...). "Nesses dois casos, há a projeção de um modelo de sociedade - o da metrópole-e é a partir desse modelo que se pensa o que poderia ser feito no Brasil", afirma o pesquisador da UFAC. Segundo ele, Oswald traça uma linha de fuga dessas abordagens ao dialogar e responder a elas: "Ele inverte a questão: no lugar de perguntar como a jovem nação brasileira deveria responder à injunção modernizadora do Ocidente, Oswald afirma que foram os indígenas (no sentido de 'nativos') daqui que deram aos europeus o horizonte a partir do qual se tornou possível elaborar as ideias que foram o motor das utopias modernas".

Ou seja, pela antropofagia, o que já se produzia no Brasil em ciência e em poesia já estava à frente do que a Europa sonhava em produzir: "Para ele o rito antropofágico tupinambá era a organização sensível de uma verdadeira weltanschauung (visão de mundo) que antecipava em muito uma descida da razão ao corpo que só ocorreria definitivamente na Europa com Marx, Nietzsche ou Freud", aponta.

PERSPECTIVISMO AMERÍNDIO A tipificação e a administração de populações "marginais", paradigma de uma antropologia de "tradição racialista" teria quase se imposto como hegemônica não fosse o contato e o diálogo com as populações tradicionais. No caso da história dessa disciplina, o alemão adotado e rebatizado pelos Apapokuva-Guarani como Curt Nimuendaju (1883-1945) teve papel fundamen- 
tal na produção de uma tradição de pensamento engajada com a luta pela emancipação e autodeterminação de coletivos "não modernos" ou "minoritários", tradição que teria impacto no trabalho de autores como Darcy Ribeiro e Florestan Fernandes, entre outros. "Curt Nimuendaju percorreu o Brasil e registrou de maneira ímpar a riqueza e a complexidade dos modos de viver e de pensar de diversos coletivos indígenas", conta Matos.

Quando, já nos anos 1990, Tânia Stolze Lima e Eduardo Viveiros de Castro elaboram o conceito de perspectivismo amerindio, a antropologia brasileira entra em um debate horizontal com o melhor que havia se produzido na antropologia inglesa ou francesa desde a década de 1980: "Vemos novamente como o diálogo cuidadoso com as populações indígenas brasileiras pode lançar nossa produção científica a uma posição de vanguarda na produção acadêmica mundial", constata o antropólogo. "O que é interessante observar, nesse caso, é que o conceito de perspectivismo, assim como o que nos traz a obra de Nimuendaju, diz respeito justamente às formações filosóficas indígenas que Oswald de Andrade tematizou sob a ideia de antropofagia: trata-se de uma abertura à diferença, e da consciência de que a diferença (ou a sociobiodiversidade) é imprescindível para uma vida que valha a pena ser vivida. Daí o famoso dizer do Manifesto antropófago: 'só me interessa o que não é meu'", finaliza Matos.

Mariana Garcia de Castro Alves

\section{ECONOMIA}

\section{ALÉM DOS SABERES E FAZERES: O IMPACTO SOCIAL E ECONÔMICO DA INDÚSTRIA CRIATIVA}

Em novembro de 2019 a Organização das Nações Unidas (ONU) declarou 2021 como Ano Internacional da Economia Criativa para o Desenvolvimento Sustentável. A proposta reconhece a necessidade de promover um crescimento econômico inclusivo e sustentado, promover a inovação e oferecer oportunidades, benefícios e empoderamento para todos e respeito por todos os direitos humanos e a necessidade contínua de apoiar países em desenvolvimento e países com economias em transição para diversificar a produção e as exportaçôes, inclusive em novas áreas de crescimento sustentável, inclusive indústrias criativas.

No Brasil, a economia criativa vem crescendo anualmente, com perspectiva de girar mais de US\$ 40 bilhôes até 2021, com impacto na vida de mais de 835 mil profissionais e inclusão de diferentes grupos sociais. A Federação das Indústrias do Estado do Rio de Janeiro (Firjan), que elabora o Mapeamento da Indústria Criativa no Brasil, divide o setor em quatro grandes áreas: consumo (design, arquitetura, moda e publicidade \& marketing), mídias (editorial e audiovisual), cultura (patrimônio e artes, música, artes cênicas e expressões culturais) e tecnologia ( $\& \& D$, biotecnologia e TIC). De acordo com o Mapeamento de 2019, o consumo $(43,8 \%)$ e a tecnologia $(37,1 \%)$ responderam por aproximadamente $80 \%$ dos trabalhadores criativos no Brasil. Acelerado pelas novas tecnologias na década passada, a economia criativa abriu espaço para a geração de novas ideias e comportamentos de criação e, consequentemente, para a forma de consumirmos produtos e serviços. Hoje, o impacto da economia criativa na atividade econômica brasileira é extremamente relevante. $\mathrm{O}$ número de novos empregos é crescente: entre 2015 e 2017, cerca de 1,7 milhão de postos de trabalho tradicionais foram perdidos no país. Nesse mesmo período, mais de 25 mil novas vagas para dez profissões dentro da economia criativa foram criadas. A expectativa é que a economia criativa brasileira atinja US\$ 43,7 bilhões até 2021.

INCLUSÃo Para Sâmia Torresini, diretora da Artesano, que comercializa mel artesanal, esse nicho da economia é importante por valorizar o trabalho manual, alavancar o consumo consciente e dar espaço para diferentes grupos e minorias. Já Karina Rossi, uma das sócias da Rede Manual, grupo 